\title{
Estimated Fetal Weight: Comparison of Clinical Versus Ultrasound Estimate
}

\author{
Anshumala Joshi, ${ }^{1}$ Om Biju Panta, ${ }^{2}$ Basanta Sharma ${ }^{1}$ \\ ${ }^{1}$ Nepal Medical College Teaching Hospital, Kathmandu, Nepal, ${ }^{2}$ Koshi Zonal Hospital, Morang, Nepal.
}

\begin{abstract}
Background: Accurate estimation of fetal weight is of paramount importance in the management of labour and delivery.

Methods: This was a cross sectional study conducted over a period of 6 months in a tertiary care teaching hospital. All singleton term mothers with cephalic presentation and intact membranes with ultrasound examination done within a week were included in the study. IUFD, multiple gestation, malpresentation, diagnosed oligohydramnios or polyhydramnios, pelvic and or abdominal masses, and current weight more than $80 \mathrm{Kgs}$ were excluded from the study. Expected fetal weight was estimated by clinical method (Johnson's formula), which was compared with Ultrasound weight estimation (Hadlock method) and actual birth weight.
\end{abstract}

Results: The estimated mean birth weight by clinical method was $3492.75 \pm 393.16 \mathrm{~g}$, by Ultrasound was $3230.02 \pm 407.22 \mathrm{~g}$ and actual mean birth weight was $3236.32 \pm 472.87 \mathrm{~g}$. The estimated birth weight by ultrasonographic method showed slightly stronger positive correlation $(\mathrm{r}=0.54 ; \mathrm{p}<0.001)$ with actual birth weight as compared to the clinical method $(\mathrm{r}=0.44 ; \mathrm{p}<0.001)$. The error of estimation of weight by clinical method showed significant negative correlation $(r=-0.24 ; p=0.01)$ with gestational age, however ultrasonographic method did not show significant correlation $(r=+0.045 ; \mathrm{p}=0.64)$. The sensitivity and specificity of clinical method and ultrasonographic method for identifying fetal birth weight above 3500 gm was $69.23 ; 65.67 \%$ and $46.15 ; 80.60 \%$, respectively.

Conclusions: Ultrasound was more reliable method to establish fetal weight at term and more consistent in various period of gestations. Clinical method can be reliably used to screen large babies in centers where ultrasound has limited availability.

Keywords: Clinical fetal weight estimation; Hadlock's method; Johnson's formula; ultrasound fetal weight estimation.

\section{INTRODUCTION}

A labour that is unduly prolonged is likely to give rise to one or more of the three types of distress, namely: fetal, maternal or obstetrician's distress. Of the three, the last may be easily the most dangerous. The major identifiable causes of failure to progress are cephalopelvic disproportion (CPD), ineffective uterine contractions and poor maternal effort in second stage. ${ }^{1}$

To rule out CPD, an accurate estimation of fetal weight is important. This particularly is important in the management of diabetic pregnancy, vaginal birth after caesarean section and breech presentation. In preterm deliveries and intrauterine growth restriction, perinatal counseling on the likelihood of survival, the intervention taken to postpone delivery, optimal route of delivery or the level of hospital where delivery should occur is completely based on the estimated fetal weight. ${ }^{2}$

In recent years, the prevalence of macrosomia worldwide has been increasing to 4.7 to $13.1 \%{ }^{3}$ According to a study conducted by Upadhyay et al, ${ }^{4}$ the incidence of macrosomic babies among the Sherpa/ Tamang community women was $10.2 \%$. This hospital attends to a large number of women belonging to this community. Caesarean delivery may be necessary if the fetus is too large to travel through the pelvis (feto-pelvicdisproportion) in an attempt to avoid birth trauma. ${ }^{5}$ Fetal macrosomia is associated with maternal morbidity, shoulder dystocia, birth asphyxia and birth trauma. ${ }^{6}$ 
Despite its accuracy, sonography used for detection of fetal growth restriction has false negative findings. The purpose of the study is to compare the accuracy of ultrasound and clinical method for estimation of fetal weight.

\section{METHODS}

This was a cross sectional hospital based study conducted over a period of six months from January 2015 to June 2015 in Nepal Medical College Teaching Hospital (NMCTH), Kathmandu, Nepal.

All singleton term mothers with cephalic presentation and intact membranes were considered for the study. Since not all women coming to our centre could afford repeated scans, only those mothers who had scans done within one week of delivery were analysed, the rest were excluded from the study. Also women with IUFD, multiple gestation, malpresentation, diagnosed oligohhydramnios or polyhydramnios, pelvic and or abdominal masses, and current weight more than $80 \mathrm{kgs}$ were excluded from the study. The ultrasound fetal weight was estimated with the Hadlock formula using a combination of the biparietal diameter (BPD), abdominal circumference $(A C)$, and femoral length (FL). A hundred and six women fulfilled the criteria.

Clinical weight estimation was done after emptying her bladder and centralizing the uterus, if needed. The mother was asked to lie down supine with extended legs and symphysio-fundal height (SFH) was measured using a tape in inches and converted into centimeters.

Using the Johnson's formula: fetal weight $(\mathrm{gm})=$ fundal height $(\mathrm{cm})-\mathrm{n} \times 155$.

Where ' $n$ ' = 13 when presenting part is above the level of ischial spines

12 if at the level of ischial spine

11 if below the level of ischial spine. ${ }^{2}$

Data was entered into Statistical Package for Social Sciences (SPSS) computer software version 18 .0 for windows. Data analysis was done using the paired student's ' $t$ ' test and the Chi-square test as appropriate.

Accuracy of the clinical or sonographic fetal weights versus (Vs) the actual birth weight were measured using percentage error, absolute error and proportion of estimates within $10 \%$ of actual birth weight (birth weight $\pm 10 \%)$.
Percentage error of the method was calculated using the formula - percentage error $=x / A X 100$;

Where $\mathrm{x}=$ error in grammes, $\mathrm{A}=$ actual birth weight.

\section{RESULTS}

Out of the 106 women studied, $58.6 \%$ were primigravidas and $41.4 \%$ were multigravidas. The mean maternal age was 24.78 , with minimum age being 16 years and maximum being 40 years. The mean gestational age was 39.59 , with a minimum gestational age being 37 weeks and maximum being 42 weeks. Most of the women (74\%) had normal delivery, and the rest $(26 \%)$ had caesarean section.

The mean estimated birth weight by ultrasonography was $3230.02 \pm 407.22$ gms; by clinical method was $3492.75 \pm 393.16$ gms and actual mean birth weight was $3236.32 \pm 472.87$ gms (Table 1 ). The estimated mean birth weight by clinical method was significantly different from actual birth weight $(p<0.001)$ while the estimated mean birth weight by ultrasonographic method was not statistically different from actual birth weight $(p=0.872)$. The estimated birth weight by ultrasonographic method showed slightly stronger positive correlation $(r=0.54$; $p<0.001$ ) with actual birth weight as compared to the clinical method $(r=0.44 ; p<0.001)$ (Figure 1$)$.

\begin{tabular}{|c|c|c|c|}
\hline & $\begin{array}{l}\text { Clinical } \\
\text { weight }\end{array}$ & USG weight & $\begin{array}{l}\text { Actual } \\
\text { weight }\end{array}$ \\
\hline Mean & 3493 & 3230 & 3236.32 \\
\hline SD & 393.1 & 407.22 & 427.87 \\
\hline Minimum & 2712.5 & 2395 & 2200 \\
\hline Maximum & 4495 & 4335 & 4250 \\
\hline
\end{tabular}

The net mean error in clinical weight estimation was $415.65 \pm 283.54$ gms and that by ultrasonograhic method was $312.40 \pm 252.15$ gms. The mean clinical weight estimation showed significantly higher error than ultrasonograhic weight estimation (Table 3). The net mean error was less than 300 gms in $58(54.7 \%)$ of ultrasonograhic estimate and $38(35.8 \%)$ of clinical estimate.

The error of estimation of weight by clinical method showed significant negative correlation $(r=-0.24$; $p=0.01$ ) with gestational age, however ultrasonographic method did not show significant correlation $(r=+0.045$; $\mathrm{p}=0.64)$. 
Table 2. Error in estimation of weight by clinical and ultrasonologicmethod.

\begin{tabular}{|llll} 
& Clnical Method & Ultrasonologic Method & p-value \\
\hline Mean error* & $415.65 \pm 283.54$ & $312.40 \pm 252.15$ & 0.007 \\
Maximum error & +810 to $-1375 \mathrm{~g}$ & +1085 to $-838 \mathrm{~g}$ & \\
Minimum error & +12.5 to $-12.5 \mathrm{~g}$ & +1 to $-16 \mathrm{~g}$ & \\
Mean percentage error* $^{*}$ & $13.72 \pm 11.01$ & $9.58 \pm 7.68$ & 0.001 \\
\hline
\end{tabular}

*Mean error was calculated by taking all error (both under and overestimation) as positive value.

Table 3. Net mean error according to gestational age in ultrasonologicand clinical method.

\begin{tabular}{|llll|}
\hline Period of Gestation & Ultrasonologic method & Clinical Method & p-value \\
\hline $37(\mathrm{~N}=6)$ & $380.07 \pm 321.70$ & $543.33 \pm 292.34$ & 0.507 \\
\hline $38(\mathrm{~N}=14)$ & $208.00 \pm 213.54$ & $488.93 \pm 339.25$ & 0.001 \\
$39(\mathrm{~N}=27)$ & $259.37 \pm 176.61$ & $472.30 \pm 290.20$ & 0.003 \\
\hline $40(\mathrm{~N}=30)$ & $326.43 \pm 271.71$ & $382.40 \pm 259.96$ & 0.27 \\
$41(\mathrm{~N}=28)$ & $394.18 \pm 279.76$ & $316.61 \pm 243.39$ & 0.207 \\
\hline $42(\mathrm{~N}=1)$ & 86.0 & 865.0 & \\
\hline
\end{tabular}

Table 4. Percentage error in various methods.

\begin{tabular}{|lllll|}
\hline & Clinical & $\begin{array}{l}\text { Cumulative } \\
\text { percentage }\end{array}$ & Ultrasonologic & $\begin{array}{l}\text { Cumulative } \\
\text { frequency }\end{array}$ \\
\hline Upto $5 \%$ & $25(23.6 \%)$ & 23.6 & $39(36.8 \%)$ & 36.8 \\
\hline $5-10 \%$ & $20(18.9 \%)$ & 42.5 & $20(18.9 \%)$ & 55.7 \\
$10-15 \%$ & $28(26.4 \%)$ & 68.9 & $21(19.8 \%)$ & 75.5 \\
\hline $15-20 \%$ & $12(11.3 \%)$ & 80.2 & $16(15.1 \%)$ & 90.6 \\
$20-25 \%$ & $6(5.6 \%)$ & 85.8 & $4(3.8 \%)$ & 94.3 \\
\hline$>25 \%$ & $15(14.2 \%)$ & 100 & $6(5.7 \%)$ & 100 \\
\hline Acceptable error $(<10 \%)$ bold highlighted and underlined. & & & \\
\hline
\end{tabular}

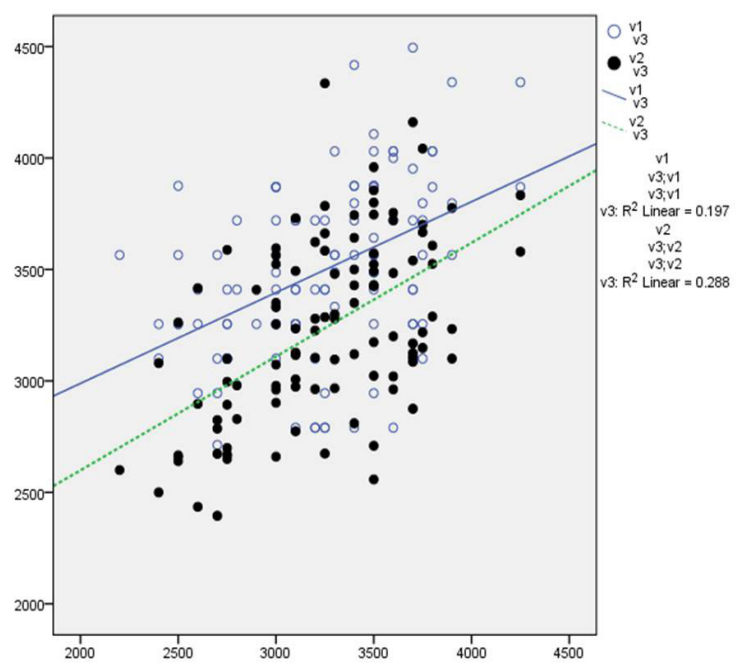

Figure 1. Scatter plot showing correlation of estimated birth weight by Ultrasonologic and clinical method with actual birth weight. ( 1 1- estimated birth weight by clinical method; v2- estimated birth weight by Ultrasonologic method; V3 actual birth weight).

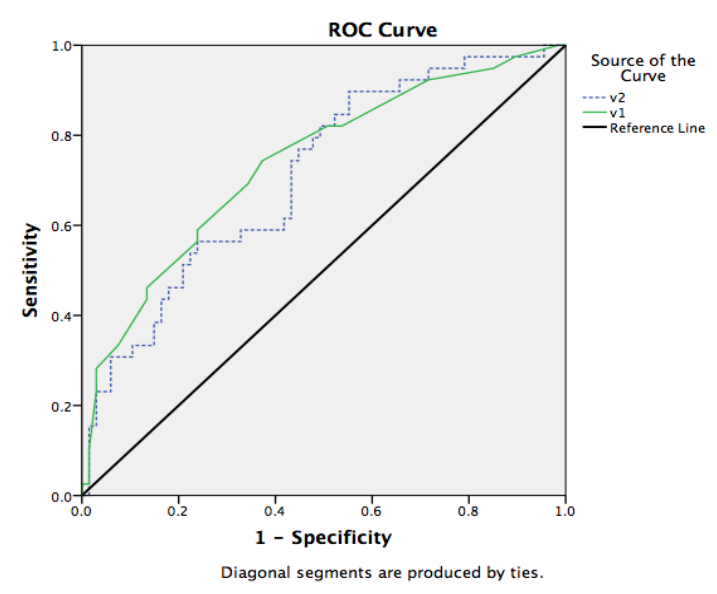

Figure 2. ROC curve for Clinical and Ultrasonologic Estimate for determining fetal macrosomia( $>3500$ gm). v1- clinical estimate; v2- Ultrasonologic estimate.

Also the mean error was significantly different between various gestational ages in clinical estimation $(p=0.025$; 
$\mathrm{F}=2.69$ ); however, it did not show significant difference in ultrasonographic estimation. There was significant difference in mean error between ultrasonograhic and clinical methods in gestational age 38 and 39 while no such difference was observed in other groups(Table5). The mean percentage error was higher, $13.72 \pm 11.01 \%$ in clinical estimation and $9.58 \pm 7.68 \%$ in ultrasonographic estimation $\quad(p=0.001)$. Considering $10 \%$ error as acceptable, clinical estimation had $42.5 \%$ within the acceptable error range and ultrasonographic method had $55.7 \%$ within the acceptable error range(Table 6).

The sensitivity and specificity of clinical method and ultrasonographic method for identifying fetal birth weight above 3500 gm was $69.23 ; 65.67 \%$ and 46.15 ; $80.60 \%$ respectively. Larger babies were slightly better identified by clinical method (AUC- $0.732 \mathrm{Cl}-0.64-0.84$ ) than ultrasonograhic method $(0.712 \mathrm{Cl}-0.61-0.81)$ as determined by area under the curve ROC method (Figure 2).

\section{DISCUSSION}

Estimation of fetal weight by ultrasonography has been the acceptable method in most centers. Clinical birth weight estimation by Johnson's and Dawn's formulas is now becoming obsolete. In poor economic countries like ours, ultrasound availability is limited to few secondary care and tertiary care centers and affordability is an issue before recommending an investigation; so clinical birth weight estimation may be an alternative tool to screen patients likely to have complications associated with labour dystocia at delivery. Also at times, we have women coming only to deliver, with no prior checkups or scans done anywhere.

The estimated birth weights by both clinical and ultrasonograhic method correlated positively with actual birth weight. However, the correlation coefficient in our study was lower than reported in previous studies. ${ }^{6,7}$ Our study also demonstrated significant difference in mean between clinically estimated birth weight and actual birth weight, however, no significant difference was seen in ultrasonographic estimate, thus demonstrating ultrasound estimate to be more reliable than clinical method. Previous studies comparing estimated clinical ultrasonographic birth weights have varying results, some favoring ultrasound, ${ }^{8}$ and some showing no advantage of ultrasound over clinical methods. ${ }^{6,7}$

The mean absolute error and percentage error in our study was higher in clinical estimation than ultrasound estimation. Similar results with lower average absolute error in ultrasound as compared to clinical estimate have been established by some previous studies. ${ }^{6,10}$ However, other studies have established similar efficacy of clinical method and ultrasound. ${ }^{7,8}$ The mean absolute error in ultrasound is comparable to previous estimate from Nepal by Bajracharya et al. ${ }^{9}$

This study also demonstrated the negative correlation of clinical estimation with gestational age thus making clinical method better as the gestational age advanced. However, ultrasound estimation was not correlated with gestational age demonstrating reliability of ultrasound in wide range gestational ages.

The percentage error in this study in both clinical and ultrasonographic method was comparable to previous similar studies. ${ }^{7,8}$ However study done in Nigeria by Ugwu et al., showed higher percentage error in clinical examination group. ${ }^{8}$ Also the absolute percentage error in our study was higher for clinical estimation than radiologic estimation, similar to findings of previous studies by Ugwu et al., ${ }^{8}$ and in contrast, other previous studies report no significant difference in percentage error between the two estimates. Only 56\% and $43 \%$ respectively were within $10 \%$ of actual birth weight in radiologic and clinical estimate. This is quite low in our study as compared to previous studies. ${ }^{6,7}$ Study done by Bajracharya et al., in Nepal showed slightly higher proportion $(60 \%)$ of ultrasound estimate within $10 \%$ of actual birth weight. ${ }^{10}$ The variation in error in ultrasound and clinical estimation of birth weight is a factor of large intra- and inter observer variability. This variability must be minimized if estimated birth weight is to be made clinically useful. Averaging of multiple repetitive measurements, equipment calibration, improvement of image quality and careful design and refinement of measurement method can help reduce the variability to certain extent.

The sensitivity of clinical method for identifying babies $>3500$ gms was higher in the clinical examination group, however the specificity was higher for ultrasonographic estimate. This represents the fact that clinical method may be more useful to use as a screening tool to identify patient at risk of labour dystocia. Previous studies estimated sensitivity of ultrasound to be higher than clinical method for detecting birth weight below 3000. ${ }^{11}$ Previous studies have also identified the superiority of ultrasound over clinical method for estimation of fetal weight especially in low birth weight babies, with no added advantage over clinical method in normal or macrosomic babies. ${ }^{6}$ There is large variation in correctly identifying macrosomic fetuses and interventions based on estimates of fetal weight also has not shown to reduce the incidence of labour dystocia and do not decrease 
adverse outcomes attributable to fetal macrosomia. ${ }^{12}$

This study only used the Johnson's formula for clinical fetal weight estimation. AG X SFH method for fetal weight estimation was not calculated in this study which has been shown by other studies to be better clinical weight estimation method. ${ }^{2,10}$ Sample size was small and was based in only one hospital, a large sample size with multicentric study would be better to establish the actual diagnostic value of the clinical and ultrasound weight estimation. This study had a small numberof underweight and macrosomic babies, thus was unable to predict diagnostic value to detect underweight and macrosomic fetuses.

\section{CONCLUSIONS}

Ultrasound was more reliable method to establish fetal weight at term and more consistent in various period of gestations. Clinical method was more reliable at advanced gestational age. Clinical method had as good as or better diagnostic value than ultrasound in detecting large babies (>3500 gm). Clinical method can be reliably used to screen large babies in centers where ultrasound has limited availability.

\section{REFERENCES}

1. Misra R. Ian Donald's practical obstetric problem, 6/e. BI Publications Pvt Ltd; 2006:506-21.

2. Sharma N, Srinivasan KJ, Sagayaraj MB, Lal DV. Fetal weight estimation methods - clinical, sonographic and MRI imaging. IJSRP. 2014 Jan;4(1):2250-3153.

3. Yang S, Peng A, Wei S, Wu J, Zhao J, Zhang Y, et al. Pre-pregnancy body mass index, gestational weight gain, and birth weight: a cohort study in China. PloS One. 2015 Jun 26;10(6):e0130101. [PubMed]

4. Upadhyay S, Biccha RP, Sherpa MT, Shrestha S, Panta PP. Association between maternal body mass index and the birth weight of neonates. Nepal Med Coll J. 2011 Mar;13(1):42-5. [PubMed]
5. Numprasert W. A study in Johnson's formula: fundal height measurement for estimation of birth weight. AU JT. 2004 Jul;8(1):15-20.

6. Shittu AS, Kuti O, Orji EO, Makinde NO, Ogunniyi $\mathrm{SO}$, Ayoola $\mathrm{OO}$, et al. Clinical versus sonographic estimation of foetal weight in southwest Nigeria. J Health, Popul Nutr. 2007 Mar;25:14-23. [PubMed]

7. Njoku C, Emechebe C, Odusolu P, Abeshi S, Chukwu $\mathrm{C}$, Ekabua J. Determination of accuracy of fetal weight using ultrasound and clinical fetal weight estimations in Calabar South, South Nigeria. Int Sch Res Notices. 2014 Nov 10;2014:970973. [PubMed]

8. Ugwu EO, Udealor PC, Dim CC, Obi SN, Ozumba BC, Okeke DO, Agu PU. Accuracy of clinical and ultrasound estimation of fetal weight in predicting actual birth weight in Enugu, Southeastern Nigeria. Niger J Clin Pract. 2014;17(3):270-5. [PubMed]

9. Bajracharya J, Shrestha NS, Karki C. Accuracy of prediction of birth weight by fetal ultrasound. Kathmandu Univ Med J. 2012 Apr-Jun;10(38):74-6. [PubMed]

10. Dudley NJ. A systematic review of the ultrasound estimation of fetal weight. Ultrasound Obstet Gynecol. 2005 Jan;25(1):80-9. [PubMed]

11. Peregrine E, O'brien P, Jauniaux E. Clinical and ultrasound estimation of birth weight prior to induction of labor at term. Ultrasound Obstet Gynecol. 2007 Mar;29(3):304-9. [PubMed]

12. Sacks DA, Chen W. Estimating fetal weight in the management of macrosomia. Obstet Gynecol Surv. 2000 Apr;55(4):229-39. [PubMed] 